\title{
Análisis comparativo de normativas de teletrabajo en América Latina
}

\author{
Comparison of telework policy in Latin America.
}

\author{
Angel Ernesto Jiménez Bernardino \\ Universidad de Guadalajara, \\ mxangeljim@hotmail.com
}

\section{Resumen}

Los sistemas de educación a distancia han improvisado algunas normativas para regular situaciones de hecho, en la mayoría de las ocasiones se resuelven situaciones bajo criterios que inicialmente fueron ideados para los sistemas educativos presenciales, bajo este tenor se hace necesaria la regulación de una figura denominada Teletrabajo, que implica el elaborar normas dirigidas a dirimir controversias y a cubrir lagunas jurídicas de trabajadores que prestan sus servicios fuera del local de la empresa y empleando las tecnologías de la información y comunicación. En América Latina existen algunos proyectos de ley, leyes aprobadas y decretos sobre esta temática, se analizan de manera muy general los casos de Argentina, Colombia, Costa Rica y México. Aunque el análisis se limita al estudio de la figura del teletrabajador en general, no se aterriza en la figura del teledocente, pero se hace evidente el atraso jurídico que nuestro país tiene con respecto a la regulación del teletrabajo a pesar de que este se incorpora en la última reforma laboral de 2013 propuesta por el Presidente de la República.

Palabras clave: Teletrabajo, laguna jurídica, ley, decretos, propuesta de ley, teletrabajador.

\section{Abstract}


The distance education systems have improvised some regulations to regulate situations in fact, in most cases resolve situations under criteria that were initially designed for educational systems face under this wording is necessary to regulate a figure called Telecommuting, which involves developing rules to settle disputes and to cover loopholes workers who provide their services outside the company premises and employing information technologies and communication. In Latin America there are a number of bills, laws and decrees adopted on this subject, are discussed in very general cases of Argentina, Colombia, Costa Rica and Mexico. Although the analysis is limited to the study of the figure of the teleworker in general, no lands in figure teledocente but legal backwardness evident that our country has with respect to the regulation of telework Although this is incorporated into the latest labor reform of 2013 proposed by the President of the Republic.

Key words: Teletrabajo, laguna jurídica, ley, decretos, propuesta de ley, teletrabajador.

Fecha recepción: Diciembre 2012

Fecha aceptación: Marzo 2013 


\section{Introducción}

Los docentes que prestan sus servicios en sistemas de educación a distancia muchas veces tiene que improvisar los criterios normativos de su actividad, al menos en México hay cuestiones que no se detallan y permiten la improvisación en la solución de controversias y de otros aspectos triviales pero que no obedecen a criterios normativos adecuados, sobre esto se trata este trabajo, entre los aspectos controversiales se encuentran:

Los mecanismos para medir las jornadas laborales, los riesgos de trabajo, el costo del mantenimiento del equipo y los gastos de conexión, además de la obligación de proporcionar los insumos, otro aspecto relevante es la disposición de tiempo en una jornada determinada de manera esporádica, la discriminación en el salario y posibilidades de ascenso y capacitación, la verificación de los lugares o locales donde se presta el servicio, las normativas aplicables al teletrabajo transfronterizo, así como las políticas públicas para su implementación en los sectores público y privado.

Por un lado se analizan de manera muy general las normativas sobre teletrabajo que existen en Argentina a través de dos ordenamientos, se estudian tres cuerpos normativos de Costa Rica y uno de Colombia. Se establecen los puntos que consideran estas normativas y finalmente se hace alusión a la propuesta mexicana a través de la iniciativa de reforma laboral de 2013 propuesta por el Presidente de la República, donde ya se incorpora la figura del teletrabajo en la ley laboral.

Se han elegido los cuerpos normativos de Argentina, Costa Rica y Colombia porque a juicio del autor representan los casos actuales y vigentes de mayor avance jurídico en la consideración del Teletrabajo en América Latina, además en el caso de Costa Rica es el último proyecto específico sobre el tema, aún no ha sido aprobado, pero representa una norma muy completa que aparentemente incorpora los avances y logros de las normas que le preceden. 
Las leyes que se revisan:

\begin{tabular}{|c|c|}
\hline Argentina & $\begin{array}{l}\text { Régimen Jurídico del Teletrabajo en Relación de Dependencia, en } \\
\text { cumplimiento de la Ley Nacional } 25800 \text { que ratifica el convenio no. } 177 \text { sobre } \\
\text { trabajo a domicilio de la Organización Internacional del Trabajo (O.I.T.) }\end{array}$ \\
\hline Argentina & 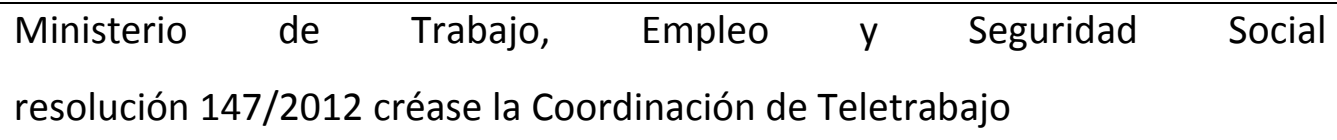 \\
\hline Costa rica & $\begin{array}{l}\text { Proyecto de ley para la Promoción, Regulación e Implementación del } \\
\text { Teletrabajo en Costa Rica expediente n. } 018.549\end{array}$ \\
\hline Costa rica & $\begin{array}{l}\text { Decreto № 34704-mp-mtss promoción del teletrabajo en las instituciones } \\
\text { públicas. }\end{array}$ \\
\hline Costa rica & $\begin{array}{l}\text { Decreto 35434-S-MTSS. Implementación del teletrabajo en mujeres que se } \\
\text { encuentren en estado de embarazo que presten servicios en instituciones } \\
\text { públicas y empresas públicas del estado y todas las empresas del sector } \\
\text { privado. }\end{array}$ \\
\hline Colombia & $\begin{array}{l}\text { Ley } 1221 \text { de } 2008 \text { por la cual se establecen normas para promover y regular } \\
\text { el teletrabajo y se dictan otras disposiciones. }\end{array}$ \\
\hline México & $\begin{array}{l}\text { Anteproyecto de iniciativa que reforma, adiciona y deroga diversas } \\
\text { disposiciones de la ley federal del trabajo de agosto de } 2012\end{array}$ \\
\hline
\end{tabular}

Desarrollo del análisis

Para la descripción de estas leyes, se considera como partes tanto al patrón como teletrabajador, por equipo se entienden los dispositivos necesarios para el desempeño del trabajo, por reversibilidad la situación de que un trabajador que adopta la modalidad de teletrabajador pueda invertirse a su estado anterior, por trabajador en general al trabajador que no se incorpora en la figura del teletrabajador, por teletrabajo mixto aquel que se desarrolla tanto en el local o establecimiento dispuesto por el patrón y que combina el teletrabajo. 
Tabla 1Tres casos de cuerpos normativos sobre teletrabajo en países latinoamericanos

\begin{tabular}{|c|c|c|c|}
\hline País & Argentina & Argentina & Costa Rica \\
\hline Norma & 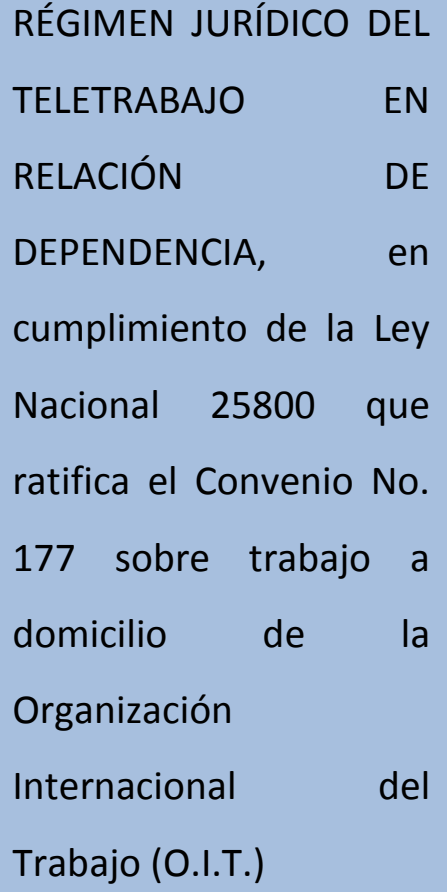 & $\begin{array}{l}\text { Resolución 147/2012 } \\
\text { Créase la } \\
\text { Coordinación de } \\
\text { Teletrabajo por el } \\
\text { MINISTERIO DE } \\
\text { TRABAJO, EMPLEO Y } \\
\text { SEGURIDAD SOCIAL }\end{array}$ & $\begin{array}{lr}\text { PROYECTO DE LEY } \\
\text { PARA LA PROMOCIÓN, } \\
\text { REGULACIÓN } \\
\text { IMPLEMENTACIÓN } \\
\text { TELETRABAJO } \\
\text { COSTA } \\
\text { Expediente N. } & \text { RIC.549 }\end{array}$ \\
\hline $\begin{array}{l}\text { Situación } \\
\text { jurídica }\end{array}$ & $\begin{array}{l}\text { Ley aprobada por el } \\
\text { Congreso }\end{array}$ & $\begin{array}{l}\text { Resolución del } \\
\text { Ministerio } \\
\text { Trabajo }\end{array}$ & Proyecto de Ley \\
\hline Fecha & 2 julio 2007 & 10 febrero 2012 & agosto de 2012 \\
\hline $\begin{array}{l}\text { Número de } \\
\text { Artículos }\end{array}$ & 9 & 3 & 22 \\
\hline
\end{tabular}


Tabla 2 Tres casos de cuerpos normativos sobre teletrabajo en países latinoamericanos

\begin{tabular}{|c|c|c|c|}
\hline País & Costa Rica & Costa Rica & Colombia \\
\hline Norma & $\begin{array}{l}\text { DECRETO No 34704-MP- } \\
\text { MTSS PROMOCIÓN DEL } \\
\text { TELETRABAJO EN LAS } \\
\text { INSTITUCIONES PÚBLICAS } \\
\text { DE COSTA RICA }\end{array}$ & 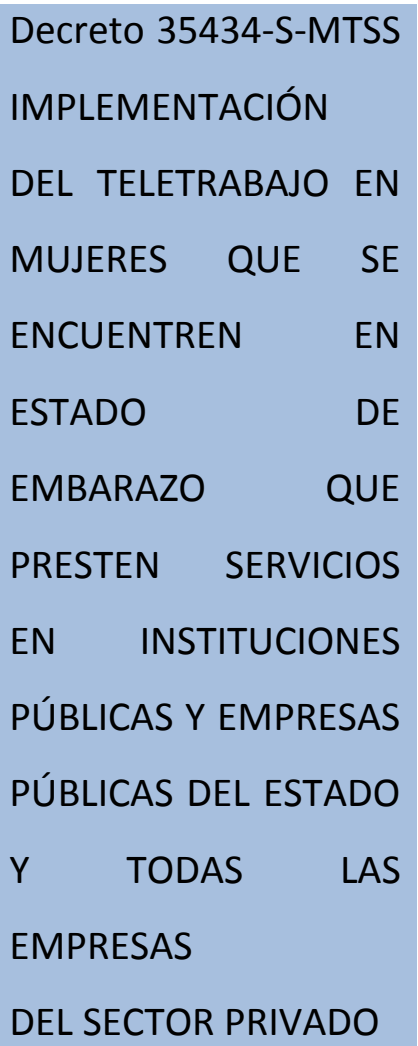 & $\begin{array}{l}\text { LEY } 1221 \text { DE } 2008 \\
\text { por la cual se } \\
\text { establecen normas } \\
\text { para promover y } \\
\text { regular el } \\
\text { Teletrabajo y se } \\
\text { dictan otras } \\
\text { disposiciones. }\end{array}$ \\
\hline $\begin{array}{l}\text { Situación } \\
\text { jurídica }\end{array}$ & Decreto & Decreto & $\begin{array}{l}\text { Ley aprobada por el } \\
\text { Congreso }\end{array}$ \\
\hline Fecha & 31 julio 2008 & 20 agosto 2009 & 16 de julio de 2008 \\
\hline $\begin{array}{l}\text { Número de } \\
\text { Artículos }\end{array}$ & 12 & 12 & 9 \\
\hline
\end{tabular}

Descripción

Argentina. Régimen jurídico del teletrabajo en relación de dependencia, en cumplimiento de la Ley Nacional 25800 que ratifica el convenio no. 177 sobre trabajo a domicilio de la Organización Internacional del Trabajo (O.I.T.). 
Artículo $1^{\circ}$, define al teletrabajo y teletrabajador, en el artículo 2 se establece la igualdad de derechos y oportunidades de los teletrabajadores con respecto a los demás trabajadores, además señala la posibilidad de convenios colectivos especiales.

En el artículo 3 se garantiza el respeto a la intimidad del teletrabajador y la privacidad de su domicilio, en el artículo 4 se establece que los gastos de mantenimiento del equipo corren a cargo del patrón siempre y cuando el equipo lo haya aportado el propio trabajador, pero admite acuerdos adicionales entre las partes. En el artículo 5 se establece la obligación del teletrabajador de cuidar y responder por los equipos cuando estos sean provistos por el patrón. En el artículo 6 se consagra la posibilidad de reversibilidad del teletrabajador que haya adoptado esta modalidad, siempre y cuando no haya manifestado su acuerdo por escrito, aunque puede hacer por acuerdo de las partes.

En el artículo 7 se hace una adecuación importante, pues determina que la autoridad administrativa deberá promover la adecuación de normas relativas a seguridad e higiene de la ley 24557 argentina sobre riesgos de trabajo para incorporar en el listado las enfermedades propias de este tipo de trabajo.

Finalmente en los artículos 8 y 9 se establece la supletoriedad de la ley de contrato de trabajo en los casos no previstos en la presente ley y se ordena su publicación.

Argentina. Resolución 147/2012 del Ministerio de Trabajo, Empleo y Seguridad Social para crear la Coordinación de Teletrabajo.

Esta resulta importante porque se crea exprofeso una coordinación para la promoción, difusión, asesoramiento, certificación de competencias de teletrabajadores, entre otras, lo cual resulta valioso para atender una modalidad laboral creciente en Argentina.

Este documento resulta importante porque impulsa un número importante de políticas de Estado para el desarrollo del Teletrabajo, estas políticas documentadas representan una base importante para generar acciones que atiendan a esta modalidad desde la generación de normas, estándares de calidad, políticas de promoción, disminución de brecha digital, incorporación al teletrabajo por grupos vulnerables, además de 
oficialmente reconocer como tarea importante la coordinación del grupo de trabajo de la eLAC1.

Esta resolución crea la denominada Coordinación de teletrabajo, cuyas funciones principales son:

Promover, monitorear y propiciar la generación de condiciones de Trabajo Decente para los teletrabajadores y promover el e-trabajo así como Impulsar el teletrabajo en las zonas más aisladas.

Asesorar permanentemente en materia de formación profesional respecto de las demandas de los sectores que requieran mejorar las competencias en TICs de los ocupados y desocupados, a fin de su incorporación a nuevas modalidades de empleo, entre ellas el teletrabajo, promover la ocupación de grupos vulnerables, entre ellos personas con capacidad disminuida, presidiarios y ex presidiarios, jóvenes de 18 a 24 años en situación de desempleo y mayores de 45 años.

Llevar adelante la ejecución del Programa de Certificación de Competencia en Teletrabajo, posibilitando la acreditación de los saberes y la experiencia adquirida informalmente por el reconocimiento de las calificaciones dentro de estándares de calidad.

Apoyar la difusión de TICs en las tramas productivas como forma de incorporar a las pequeñas y medianas empresas en procesos de innovación, fomentando su incorporación al sector formal de la economía incluyendo modalidades de teletrabajo y e-trabajo.

Coordinar la Red de Empresas e instituciones comprometidas en Teletrabajo para la cooperación en los niveles nacionales y regionales, respecto al intercambio de aprendizajes, investigaciones y buenas prácticas en teletrabajo.

${ }^{1}$ PLAN DE ACCIÓN SOBRE LA SOCIEDAD DE LA INFORMACIÓN Y DEL CONOCIMIENTO DE AMÉRICA LATINA Y EL CARIBE (eLAC2015). : El eLAC es un plan de acción para América Latina y el Caribe, acorde con los Objetivos de Desarrollo del Milenio (ODM) y la Cumbre Mundial sobre la Sociedad de la Información (CMSI), con visión de largo plazo -hacia el año 2015- que plantea que las tecnologías de la información y de las comunicaciones (TIC) son instrumentos de desarrollo económico y de inclusión social. La Comisión Económica para América Latina y el Caribe (CEPAL) actúa como Secretaría Técnica de este plan de acción regional, coordinando labores, monitoreando avances, publicando boletines informativos e intercambiando información entre los actores relevantes multi-sectoriales, En el marco del Plan de Acción eLAC2015, aprobado durante la Tercera Conferencia Ministerial sobre la Sociedad de la Información de América Latina y el Caribe, se acordó la creación de 14 grupos de trabajo.

El grupo de Teletrabajo esta coordinado por Viviana Laura Díaz, Ministerio de Trabajo, Empleo y Seguridad Social de Argentina, quien está en la presidencia y en la Vicepresidencia: República Dominicana a través de Ángela Jaquez, Cámara de Diputados, además de otros integrantes de Venezuela, Costa Rica, Colombia, México y Ecuador. 
Constituir un centro temático de referencia para el seguimiento, análisis y difusión de las transformaciones del escenario laboral vinculadas a la aplicación de las TICs para el teletrabajo.

Articular como espacio de encuentro y de diálogo entre el MINISTERIO DE TRABAJO, EMPLEO Y SEGURIDAD SOCIAL y los diferentes sectores de la sociedad civil, sector público, ámbito académico, gremios y empresas, para abordar las problemáticas de las TICs en las modalidades de teletrabajo y e-trabajo, elaborando datos y estadísticas, documentos y publicaciones.

Generar acciones destinadas a fomentar el teletrabajo dentro de la Comunidad del MERCOSUR, coma así también coordinar el Grupo de Trabajo en Teletrabajo eLAC 2011 de la CEPAL.

Impulsar la elaboración de normas que promuevan y regulen el Teletrabajo en relación de dependencia, proponer modificaciones a la Ley de Riesgos del Trabajo.

Coordinar acciones conjuntas con los MINISTERIOS DE CIENCIA Y TECNOLOGIA Y DE EDUCACION en proyectos que favorezcan la reducción de la brecha tecnológica a nivel nacional y en el diseño de herramientas de capacitación y formación en teletrabajo para docentes, profesores y alumnos de nivel Medio, Terciario y Universitario incorporando el teletrabajo como herramienta de inclusión social en todos los ámbitos alcanzados o alcanzables por esta modalidad.

Costa Rica. Proyecto de ley para la promoción, regulación e implementación del teletrabajo. Expediente $\mathrm{N}^{\circ} 18549$.

El autor tuvo la oportunidad participar en el manifiesto Costa Rica del Telework 2012, donde después de tres jornadas de trabajo diversos actores sociales: políticos, universitarios, abogados, teletrabajadores, estudiosos del tema, propusieron una serie de medidas a ser consideradas en una ley de teletrabajo para Costa Rica y en políticas públicas para el desarrollo del teletrabajo, dentro de las cuestiones importantes a destacar está este proyecto de ley que fue elaborado y presentado con antelación a la celebración de dicho congreso internacional, este proyecto representa el último esfuerzo 
de un legislador en cuanto a la regulación específica del teletrabajo en América Latina, a través de su análisis puede desprenderse que es un buen ejemplo para otros países pues incorpora: el teletrabajo como modalidad para trabajadores independientes, bajo el régimen de dependencia, para fortalecer el trabajo autónomo y para incorporar a personas con discapacidad, para operar en centros gubernamentales y para reducir los tiempos de traslados y la contaminación ambiental, también como una respuesta a la necesidad de reducir costos de energía eléctrica y agua en las oficinas de gobierno, entre otras, es decir, es una ley muy completa con una amplia visión tanto de objetivos como de su justificación, por ello es valioso su análisis, porque ofrece un buen ejemplo para los legisladores, al menos para México y esta, desde mi punto de vista, un poco más aventajada que las de los demás países latinoamericanos que ya cuentan con una ley de teletrabajo.

Esta ley ha sido compartida con quienes colaboramos en un grupo de la eLAC de la CEPAL denominado GDT (grupo de teletrabajo), no es un documento público aún, pero ello no significa que no pueda utilizarse para tomar algunas consideraciones de lo que bien puede ser la siguiente ley promulgada sobre el tema.

Incorpora definiciones, modalidades, centros de teletrabajo, políticas públicas, regulación de una agencia para promoción del teletrabajo en Costa Rica, incentivos gubernamentales para las empresas que fomentan el teletrabajo, la población con discapacidad, y desde luego las garantías y derechos de las empresas y los teletrabajadores.

Un análisis general de la ley:

El artículo 1, se refiere al objeto de la ley, mismo que se consagra en el artículo 3 de este ordenamiento.

El artículo 2 se refiere al ámbito de aplicación que corresponde en general a las instituciones gubernamentales y a las empresas públicas y privadas. En el artículo 3 se refiere al objetivo de la ley, este es importante porque incorpora las diversas finalidades de otras legislaciones latinoamericanas: el cuidado del medio ambiente, modernizar la gestión institucional, apoyo para la incorporación laboral a grupos vulnerables, impulso 
del teletrabajo y facilitar el cierre de la brecha digital en Costa Rica, esto implica un avance importante, pues en un solo cuerpo legislativo se incorporan propuestas de ley que fueron concebidas por separado tanto en Costa Rica como en otro países como Colombia.

En el artículo 4 se define al teletrabajo, que desde mi punto de vista es la definición más acertada pues incorpora a los teletrabajos como teledocente en esta definición, cuestión que por ejemplo la definición de la ley Argentina sobre la materia no es del todo correcta, lo que no menciona es la consideración del porcentaje de tiempo que se dedica a la actividad para considerarlo teletrabajo. También adopta la definición del teletrabajador tanto el que depende de un patrón que el de un trabajador autónomo. Define también TICs, pero incorpora dos definiciones más: telecentros y modernización de la gestión laboral a través del teletrabajo.

El artículo 5 resulta novedoso en las legislaciones pues explícitamente describe las políticas de teletrabajo a seguir -la llama principios rectores-:
a) Accesibilidad sin exclusión.
b) Solidaridad hacia los grupos vulnerables.
c) Cumplimiento de la normativa del trabajo y la salud ocupacional.
d) Cumplimiento de los derechos y obligaciones de los patronos y teletrabajadores.
e) Mejoramiento de la productividad organizacional.
f) Optimización en el uso de los recursos.
g) Sostenibilidad ambiental.

En el capítulo II también se establecen otras novedades si se compara esta ley con otros ordenamientos como Argentina, Colombia, Chile o Perú, pues trata de los deberes del Estado para promover el teletrabajo y crea una agencia para promoción del teletrabajo, misma que será administrada por el Comité Ejecutivo que lo conforma un representante de cada uno de los siguientes entes: Ministerio de Trabajo y Seguridad Social, Ministerio 
de Planificación, Ministerio de Ciencia y Tecnología, Ministerio de Educación Pública, Servicio Civil, sector privado y de los trabajadores, esto en los articulados 6 y 7.

En el artículo 8 se consignan las políticas públicas a seguir:

a) La infraestructura del estado existente, que sea útil para el cumplimiento de los fines establecidos en la presente ley.

b) Las tecnologías aplicadas al teletrabajo.

c) Política de inclusión social por medio del teletrabajo.

d) Responsabilidad ambiental en materia de teletrabajo.

e) Acciones formativas para desarrollar el teletrabajo.

f) Incentivos para la promoción del teletrabajo.

g) La creación de una red nacional para el fomento del teletrabajo.

h) La creación de alianzas entre el sector público y el empresarial para el fomento del teletrabajo.

Continuado con la revisión del articulado, En el artículo 9 Se establecen los incentivos gubernamentales, los cuales se especificarán en el reglamento respectivo. En el artículo 10 Se refiere a la no discriminación para la incorporación de sujetos al teletrabajo.

Artículo 11 Establece la obligatoriedad de incorporar a la plantilla de trabajadores en situación de discapacidad.

Artículos 12, 13 y 14. Se establece el fomento del teletrabajo en zonas geográficas aisladas de las zonas metropolitanas y en aquellos sectores poblacionales en condiciones socioeconómicas adversas así como jóvenes, además se consigna el respeto a la equidad de género.

A partir del capítulo IV se mencionan las garantías de los teletrabajadores:

En el artículo 15 se establece la igualdad en derechos que los demás trabajadores

El Artículo 16 establece como novedad la obligatoriedad de los patrones de proporcionar las insumos para el teletrabajo, incluyendo la información necesaria, así como los costos de conexión, mantenimiento y equipos para el desempeño del teletrabajo, salvo acuerdo 
entre ambas partes, esto también es una novedad, pues era situación ignorada en la mayoría de los proyectos sobre el tema en disposiciones latinoamericanas.

A su vez en el artículo 17 se establece la obligación de cuidar de todos estos elementos por parte del trabajador y las condiciones en que esa obligación debe ser respondida. Además indica que el trabajador debe tener disposición de tiempo hacia su patrón en cualquier momento de su jornada, cuidar la confidencialidad de la información que le es suministrada por el primero.

Otra novedad valiosa consiste en el hecho de que la ley menciona que el trabajador debe hacer caso a las recomendaciones de los profesionales de la salud ocupacional, pues incorpora elementos ignorados en otras legislaciones sobre la seguridad de las instalaciones, el diseño ergonómico. El trabajador está obligado a las demás obligaciones de un trabajador pero existen algunos aspectos que pueden acordados entre él y el patrón como la disponibilidad y el uso exclusivos de los medios para teletrabajar.

En el artículo 18 se establece la posibilidad de reversibilidad del teletrabajador a su modelo de trabajo previo, pues debe existir la voluntad del teletrabajador para fungir como tal; pero esto no aplica cuando el teletrabajador haya accedido a esa exclusivamente a esa plaza de teletrabajo desde su contratación.

El artículo 19 establece un avance más, pues en otras legislaciones se omitía muchas veces consignar un contrato que contenía las clausulas a que se sujetaban el teletrabajador y el patrón, lo que conllevaba a improvisar en muchos casos, por ello este artículo representa un avance significativo pues ahora de manera específica y diferenciada se establece un contrato que bien puede apoyarse en el contrato colectivo donde este exista, pero de manera independiente atiende aspectos que solo a los teletrabajadores le son aplicables.

El artículo 20 ofrece una novedad más, pues considera la aplicación de las normas laborales de este proyecto de ley y demás normas existentes en el país a trabajadores transfronterizos cuyo domicilio se ubica en territorio costarricense, esto representa un avance porque también existían omisiones en cuanto a la reglamentación aplicable a un teletrabajador, las cuestiones fiscales, la protección de derechos, entre otras, pues muchas veces quedaba desprotegido el teletrabajador por serias lagunas en la ley. 
En el artículo 21 se establece una política de Estado que permite dar continuidad a los esfuerzos por implementar el teletrabajo en instituciones gubernamentales, pues señala que el plan estratégico del periodo siguiente a la emisión de esta ley las acciones que se establezcan en el Plan Nacional de Desarrollo en Materia de Modernización de la Gestión por medio del Teletrabajo, lo cual es de esperar que permita desarrollar el teletrabajo desde las instituciones públicas y con los beneficios que acompañan al teletrabajo.

Finalmente en el artículo 22 se señala que esta ley debe ser reglamentada en un periodo de tres meses a partir de su publicación, por lo cual se espera que el reglamento en la materia sea más específico en aspectos por detallar.

Costa Rica. Decreto no 34704-MP-MTSS, promoción del teletrabajo en las instituciones públicas.

En el Artículo $1^{\circ}$ se establece el objeto del Decreto: promover y regular el Teletrabajo en las instituciones del Estado, como instrumento para incrementar la productividad del funcionario, el ahorro de combustibles, la protección del medio ambiente, y favorecer la conciliación de la vida personal, familiar y laboral, mediante la utilización de las Tecnologías de la Información y las Comunicaciones (TIC).

En el artículo 2 se establecen las definiciones: Teletrabajo, Instituciones del Estado, Tecnologías de la Información y Comunicaciones (TIC), Domicilio personal, Teletrabajador, Servicios no presenciales y Ofimática (Equipamiento que se utiliza para generar, almacenar, procesar o comunicar información en un entorno de oficina).

En el Artículo 3, se refiere a la Implementación de Programas de Teletrabajo dentro de las instituciones del Estado, donde señala los requisitos mínimos que deben establecerse en el programa.

En el artículo 4 se establecen las condiciones Laborales: salvo que se determine otra modalidad posteriormente, todos los programas que se implementen con base en este Decreto tendrán carácter temporal. Salvo excepciones específicas los teletrabajadores no estarán sujetos a jornadas ni horarios de trabajo, cuando desempeñen las labores en su domicilio personal o lugar habilitado a los efectos y para aquellos Teletrabajadores, que 
no estén sujetos a jornadas ni horarios de trabajo, la eficiencia y cumplimiento en las labores encomendadas a las personas teletrabajadoras se medirá de acuerdo con la producción-meta. Los Teletrabajadores mantendrán y se beneficiarán de los mismos derechos y obligaciones que tienen los demás trabajadores de la institución. Para todos los efectos y en lo que fuere aplicable, se atenderán las reglas del contrato a domicilio, regulado a partir del artículo 109 del Código de Trabajo.

En el artículo 5 se ordena la conformación de un Equipo Coordinador de los planes o programas de Teletrabajo, se indica quienes lo conformaran, en artículo 6 se establecen sus competencias y obligaciones, entre las cuáles están: emitir políticas y lineamientos generales en materia de Teletrabajo, en el sector público, coordinar las acciones necesarias con las instancias correspondientes para que el Teletrabajo se aplique a nivel nacional, incluyendo el estudio de las instituciones públicas que por su condición presupuestaria infraestructura tecnológica o actividades pueden participar en esta modalidad de trabajo; regular y normar los procedimientos, lineamientos y programas de formación y capacitación, que sean necesarios, para la debida implementación de los Programas de Teletrabajo.

De acuerdo al artículo 7 para el desarrollo y ejecución de las programas pilotos de teletrabajo en cada institución, se integrará una Comisión Institucional, quienes deberán tomar en cuenta, para la correcta ejecución interna de los programas de Teletrabajo, los siguientes componentes:

a) Infraestructura de telecomunicaciones.

b) Acceso a equipos de computación.

c) Aplicaciones y contenidos.

d) Divulgación y mercadeo.

e) Capacitación.

f) Incentivos.

g) Evaluación permanente y formulación de correctivos cuando su desarrollo lo requiera. 
En los artículos 8 y 9 se consigna de interés público las actividades que se realicen para el fomento del Teletrabajo en las instituciones públicas. Adicionalmente, la Administración Pública podrá coordinar con el sector privado acciones de cooperación, dentro de sus posibilidades y el marco legal correspondiente, y que el Equipo Coordinador podrá recomendar al Poder Ejecutivo la implementación de políticas públicas, en relación con la infraestructura tecnológica que se requiera para el desarrollo eficiente de las funciones del teletrabajador.

Se establece en el artículo 10 que los jerarcas de las instituciones del Estado facilitarán la participación de sus funcionarios en los eventos formativos para incorporarlos al Programa de Teletrabajo, y en el 11 se establece que las instituciones del Estado remitirán al Equipo Coordinador, en un plazo no mayor a tres meses, la evaluación de sus resultados.

Costa Rica. Decreto 35434-S-MTSS, Implementación del teletrabajo en mujeres que se Encuentren en estado de embarazo que presten servicios en instituciones públicas y empresas públicas del estado y todas las empresas del sector privado.

En el artículo 1을 se establece esta ley se establece que la mujer que preste servicios en instituciones públicas y empresas públicas del Estado y en cualquier empresa del sector privado, que se encuentre en estado de embarazo, podrá prestar sus servicios desde su domicilio, o lugar habilitado para esos efectos, sujeto a la naturaleza de sus funciones, de forma tal que el trabajo que desarrolla pueda realizarse en los términos del Decreto ya revisado anteriormente.

Establece el artículo 2 los requisitos que la mujer trabajadora debe cumplir para sujetarse a este ordenamiento.

El artículo 3 señala la potestad que goza el patrono o representante patronal para supervisar el trabajo desempeñado bajo esta modalidad, pero respetando los derechos de la teletrabajadora.

Se establece en el artículo 4 que la implementación de la modalidad de teletrabajo, se ha derivado de la proliferación de la influenza AH1N1, en consecuencia su aplicación será 
temporal. En los artículos 5, 6 y 7 se establece la exclusión de las presentes modalidades aquellas trabajadoras en estado de embarazo, cuyas funciones, por su naturaleza, requieran necesariamente su presencia en la sede de trabajo. Corresponderá al Ministerio de Trabajo y Seguridad Social intervenir en cualquier momento o situación durante la implementación de esta modalidad de trabajo.

En el artículo 8 se especifica que los contratos de trabajo gozarán de las mismas condiciones para las que inicialmente fue contratada la servidora, se mantendrán los mismos derechos y obligaciones estipulados en su contrato de trabajo inicial, así como otros derechos laborales adquiridos y el hecho de acogerse a esta modalidad, no interrumpe la continuidad de sus servicios ni de otro tipo de derechos.

Las instituciones públicas y empresas públicas del Estado que deban adoptar esta modalidad de trabajo, deberán conformar una comisión encargada en los términos del artículo 7 del Decreto Ejecutivo № 34704-MP-MTSS, mismo que se aplica de manera supletoria en lo no previsto en el presente decreto.

Colombia. Ley 1221 de 2008 por la cual se establecen normas para promover y regular el teletrabajo y se dictan otras disposiciones.

Un análisis general de la ley permite señalar que se establece por objeto promover y regular el Teletrabajo como un instrumento de generación de empleo y autoempleo mediante la utilización de tecnologías de la información y las telecomunicaciones (TIC). En el artículo se definen:

Teletrabajo, tanto autónomo (por ejemplo el domicilio del trabajador) como móvil (los que no tienen un lugar fijo) y suplementarios (se puede decir mixtos, teletrabajan pero acuden también a la oficina de manera regular); se define también

Teletrabajador. En este artículo se adiciona pues la diferenciación de los diferentes tipos de teletrabajadores, lo cual resulta ventajoso, pues existen muchos teletrabajos mixtos y que no necesariamente encajan en la definición de otros ordenamientos jurídicos. 
En el artículo $3^{\circ}$ se establece formalmente la política pública de fomento al teletrabajo, involucrando a diversas instancias gubernamentales que tendrá en cuenta los siguientes componentes:

Infraestructura de telecomunicaciones, acceso a equipos de computación, aplicaciones y contenidos, divulgación y mercadeo, capacitación, incentivos y Evaluación permanente y formulación de correctivos cuando su desarrollo lo requiera. Se establece también que deberá formularse una política pública de incorporación al teletrabajo de la población vulnerable (Personas en situación de discapacidad, población en situación de desplazamiento forzado, población en situación de aislamiento geográfico, mujeres cabeza de hogar, población en reclusión, personas con amenaza de su vida).

En el artículo 4 se consigna la creación de la Red nacional de fomento al teletrabajo, integrada por diversos sectores públicos y particulares, cuyas funciones serán definidas en la Política Pública de Fomento al Trabajo.

En el artículo 5 se establece que el Gobierno Nacional pondrá en funcionamiento un sistema de inspección, vigilancia y control para garantizar el cumplimiento de la legislación laboral en el marco del teletrabajo.

El artículo 6 es muy explícito y establece un avance en la consideración del teletrabajo, pues diferencia las condiciones a que se sujeta el teletrabajador, este artículo es tal vez el más importante pues de acuerdo al año en que se legisló representa un notable avance en la protección de los derechos del teletrabajador y presenta criterios para dirimir controversias, además de criterios que orientan la implementación del teletrabajo.

Señala que a los teletrabajadores no les serán aplicables las disposiciones sobre jornada de trabajo, horas extraordinarias y trabajo nocturno. No obstante la anterior, pero deberá vigilarse el que no sean sometidos a excesivas cargas de trabajo.

Garantiza la igualdad de trato y salario con respecto a un trabajador en general si desempeña el mismo trabajo, pero considerando también las posibilidades y particularidades del trabajo.

Otra novedad importante es la consideración del salario en los casos en los que el empleador utilice solamente teletrabajadores, pues deberá tomarse en consideración la 
naturaleza del trabajo y la remuneración que se paga para labores similares en la localidad.

También incorpora un criterio valioso al señalar que no se considera teletrabajador al asalariado que realice ocasionalmente su trabajo en su domicilio o en lugar distinto de los locales de trabajo del empleador, en vez de realizarlo en su lugar de trabajo habitual.

También establece que la asignación de tareas para los teletrabajadores deberá hacerse de manera que se garantice su derecho a contar con un descanso de carácter creativo, recreativo y cultural.

Literalmente la igualdad de trato garantiza el derecho de los teletrabajadores a constituir o a afiliarse a las organizaciones que escojan y a participar en sus actividades, a la remuneración, acceso a la formación, edad para emplearse, a protección de la discriminación en el empleo, respeto al derecho a la intimidad y privacidad del teletrabajador, la protección en materia de seguridad social (Sistema General de Pensiones, Sistema General de Seguridad Social en Salud y riesgos profesionales), de conformidad con lo previsto en la Ley 100 de 1993 (por la cual se crea el sistema de seguridad social integral y se dictan otras disposiciones) y demás normas aplicables. Otro particular importante es que a modo de política pública establece la protección a la maternidad protección de la maternidad, pues las teletrabajadoras tendrán derecho a retornar al mismo puesto de trabajo o a un puesto equivalente con la misma remuneración, al término de la licencia de maternidad.

Otra adición importante representa la obligación de los empleadores de proveer y garantizar el mantenimiento de los equipos, conexiones, programas, costos de energía, desplazamientos ordenados por él, necesarios para desempeñar las funciones del teletrabajador, pero también señala que los elementos y medios suministrados no podrán ser usados por persona distinta al teletrabajador, quien al final del contrato deberá restituir los objetos entregados para la ejecución del mismo, en buen estado, salvo el deterioro natural. 
Otra norma que previene posibles disputas es la consigna de que recibir el salario íntegro si el teletrabajador no recibe los paquetes de información para que realice sus labores, o los programas para desempeñar su función, o no son arreglados a pesar de haberlo advertido, igual ocurre cuando el lugar de trabajo sea suministrado por el empleador y el teletrabajador no puede realizar la prestación debido a un corte en las líneas telefónicas o en el flujo Eléctrico, sin embargo esta cuestión no aplica al trabajador que se desempeñe en la modalidad de móvil.

El empleador, debe contemplar el puesto de trabajo del teletrabajador dentro de los planes y programas de salud ocupacional y debe contar con una red de atención de urgencias en caso de accidente o enfermedad del teletrabajador en el ejercicio de sus labores.

Se establece la voluntariedad del teletrabajo para ambas partes.

Se consigna también un derecho preferente al indicar que las empresas cuyas actividades tengan asiento en Colombia, que estén interesadas en vincular teletrabajadores, deberán hacerlo con personas domiciliadas en el territorio nacional, quienes desarrollarán sus labores en Colombia y a todas las relaciones de teletrabajo que se desarrollen en el territorio nacional les será aplicada la legislación laboral colombiana, en cuanto sea más favorable para el teletrabajador.

Otra consideración importante es la posibilidad de contabilizar el pago de horas extras, dominicales y festivos como a cualquier otro trabajador en general cuando el teletrabajo sea ejecutado donde sea verificable la jornada laboral, y el teletrabajador a petición del empleador se mantiene en la jornada laboral más de lo previsto en el artículo 161 del Código Sustantivo del Trabajo y de la Seguridad Social, o le asigna más trabajo del normal. Se establece también en artículo el llevar un Registro de Teletrabajadores, donde el empleador debe informar de dicha vinculación a los Inspectores de Trabajo del respectivo municipio y a falta de este al Alcalde Municipal. Finalmente se establece que la presente ley deberá ser reglamentada. 
México. Anteproyecto de iniciativa que reforma, adiciona y deroga diversas disposiciones de la Ley Federal del Trabajo de agosto de 2012.

En el proyecto se establece: "es indispensable dar un impulso decidido a la modificación de la Ley Federal del Trabajo. Las propuestas que hoy se presentan a consideración de esa Soberanía, recogen los temas y preocupaciones más recurrentes que han manifestado trabajadores y patrones", lo cual significa que el teletrabajo y su normativa no es un tema de preocupación recurrente en México, pues la propuesta es pobre en este sentido y choca contra la tendencia Latina de normar el teletrabajo.

Dentro de las propuestas señaladas se menciona como el punto 21:

"Reconocer al teletrabajo, es decir, aquel que se realiza a distancia, utilizando tecnologías de la información y la comunicación, como una de las formas de trabajo a domicilio. Con esta modalidad se favorece la posibilidad ocupacional de las personas, pues les permite compaginar las actividades laborales con sus respectivas responsabilidades familiares. Desde luego, en la realización de este tipo de actividades cuentan con la protección de las normas de trabajo y de seguridad social".

Sin embargo en la Propuesta de Ley solo se menciona en el artículo 311 una modificación referida al teletrabajo, pero incluso sin utilizar el término para quedar así:

Artículo 311....

Será considerado como trabajo a domicilio el que se realiza a distancia utilizando tecnologías de la información y la comunicación.

Si el trabajo se ejecuta en condiciones distintas de las señaladas en este artículo se regirá por las disposiciones generales de esta Ley.

No se van a enumerar los artículos 311 a 330 que comprenden del capítulo XII de la Ley Federal del Trabajo, pero se puede afirmar en general tras su revisión:

No por el solo hecho de incorporar la noción de teletrabajo en el artículo 311 se resuelve la necesaria norma de este tópico, no se hace ninguna propuesta de modificación a ninguno de los demás artículos de este capítulo, intentando hacer congruentes estos con el artículo 311 puede interpretarse;. 
Artículo 324.- Los patrones tienen las obligaciones especiales siguientes:

II. Proporcionar los materiales y útiles de trabajo en las fechas y horas convenidos;

Lo que implica que el patrón debe proporcionar los equipos de trabajo, aunque no es posible saber si esa es la intención del legislador, pero tampoco señala que pueda hacerse mediante convenio entre las partes

En los demás artículos se garantiza la igualdad de salario, el derecho a un día de descanso y a las vacaciones anuales, aunque no menciona la flexibilidad laboral y deja abierta la posibilidad de que el trabajador pueda ser auxiliado por miembros de su familia.

\section{Conclusión}

Queda claro que la propuesta analizada en la reforma laboral de México resulta pobre, pues no se consagra ni siquiera una definición precisa, ni modalidades, instancias, políticas públicas, en pocas palabras, adolece de todo significado y pertinencia respecto a la urgente necesidad de normar el teletrabajo en nuestro país.

Es evidente lo inapropiado de la reforma en el sentido de atender las nuevas modalidades laborales, es una cuestión que contraviene directamente la tradición jurídica nacional, pues la ley laboral ha sido ejemplo histórico de avance jurídico y una disposición que ha servido para imponer criterios nivel mundial, sin embargo no se actualiza y al parecer este rezago seguirá impidiendo el desarrollo de modalidades laborales crecientes en otros países.

La norma otorga seguridad jurídica y a falta de esta se crea un Estado donde la improvisación y la aplicación de criterios diversos evita que las instituciones y empresas determinen incorporar el teletrabajo en sus prácticas laborales, con la desventaja que esto conlleva. Esto es una desventaja también para los teletrabajadores mexicanos por cuenta propia, pues quedan expuestos a las leyes de aplicación internacional debido a la laguna jurídica existente en muchos aspectos. 
El interés del autor ha sido exponer la insuficiencia de nuestra norma nacional en cuanto al teletrabajo y con respecto a otros países latinoamericanos, pero específicamente dejar una inquietud: este rezago jurídico implica también que los sistemas educativos contraten a teledocentes (que no dejan de ser teletrabajadores) y se apliquen criterios normativos destinados originalmente a trabajadores en general, lo cual puede resultar en un freno importante a los sistemas de educación a distancia, aunque esto no se demuestra en este estudio.

\section{Bibliografía}

Asamblea Legislativa (2012). Proyecto de ley para la Promoción, Regulación e Implementación del Teletrabajo en Costa Rica expediente № 18549. San José, Costa Rica

Congreso de Colombia (2008). Ley 1221 de 2008 por la cual se establecen normas para promover y regular el teletrabajo y se dictan otras disposiciones.

Ley Federal del Trabajo. Comentarios, prontuario, jurisprudencia. México: Editorial Porrúa.

Poder Ejecutivo Nacional (2007). Régimen Jurídico del Teletrabajo en Relación de Dependencia, en cumplimiento de la Ley Nacional 25800. Buenos Aires.

Presidencia de la República (2012). Anteproyecto de iniciativa que reforma, adiciona y deroga diversas disposiciones de la ley federal del trabajo. México. 